\title{
Physical activity and sedentary behavior during the early years in Canada: a cross-sectional study
}

\author{
Rachel C Colley ${ }^{1,2^{*}}$, Didier Garriguet ${ }^{1}$, Kristi B Adamo ${ }^{2}$, Valerie Carson ${ }^{3}$, Ian Janssen ${ }^{4}$, Brian W Timmons ${ }^{5}$ \\ and Mark S Tremblay ${ }^{2}$
}

\begin{abstract}
Background: Physical activity and sedentary behavior habits are established during early childhood, yet only recently has objectively measured data been available on children aged 5 years and younger. This study presents data on the physical activity and sedentary behaviors of Canadian children aged 3-5 years.

Methods: Data were collected as part of the Canadian Health Measures Survey between 2009 and 2011. A nationally-representative sample $(n=459)$ of children aged 3-5 years wore Actical accelerometers during their waking hours for 7 consecutive days. Data were collected in 60-sec epochs and respondents with $\geq 4$ valid days were retained for analysis. Parents reported their child's physical activity and screen time habits in a questionnaire.

Results: Eighty-four percent of 3-4 year old children met the physical activity guideline of 180 minutes of total physical activity every day while $18 \%$ met the screen time target of $<1$ hour per day. Fourteen percent of 5 year old children met the physical activity guideline of 60 minutes of daily moderate-to-vigorous physical activity (MVPA) while $81 \%$ met the screen time target of $<2$ hours per day. Children aged 3-4 years accumulated an average of 352 $\mathrm{min} / \mathrm{d}$ of total physical activity and 66 minutes of MVPA while 5 year old children accumulated an average of 342 $\mathrm{min} / \mathrm{d}$ of total physical activity and 68 minutes of MVPA. Children were sedentary for approximately half of their waking hours and spent an average of 2 hours per day in front of screens. Only 15\% of 3-4 year olds and 5\% of 5 year olds are meeting both the physical activity and sedentary behavior guidelines.
\end{abstract}

Conclusions: Promoting physical activity while reducing sedentary behavior is important at all stages of life. The findings of the present study indicate that there remains significant room for improvement in these behaviors among young Canadian children.

Keywords: Preschool, Pediatric, Surveillance, Ambulation, Step counts

\section{Background}

The early years represent a critical period for the establishment of active living habits; however, little is known about how much physical activity and sedentary behavior young children are accumulating. Research to date suggests that children less than 5 years of age spend a small proportion of time being active and have high levels of inactivity [1-3], although most studies historically focused on moderate-to-vigorous-intensity physical activity (MVPA) and relied on non-objective measures. A recent systematic review reported that physical activity during the early years

\footnotetext{
*Correspondence: rcolley@cheo.on.ca

${ }^{1}$ Health Analysis Division, Statistics Canada, Ottawa, Canada

${ }^{2}$ Healthy Active Living and Obesity Research Group, Children's Hospital of

Eastern Ontario Research Institute, Ottawa, Canada

Full list of author information is available at the end of the article
}

is associated with improved measures of adiposity, motor skill development, psychosocial health, and cardiometabolic health indicators [4]. High levels of sedentary behavior in this age group, in particular high levels of television viewing, is associated with increased adiposity and lower measures of psychosocial and cognitive development [5].

The National Association for Sport and Physical Education (NASPE) recommends at least one hour of structured and one or more hours of unstructured physical activity every day for children from birth to age 5 years [6]. Levels of adherence to the NASPE guidelines have varied considerably (32-79\%) and this is likely due in part to differences in measurement tools and inconsistent inclusion of light intensity physical activity [1,3,7]. Australian and Canadian guidelines recommend that young children

\section{Biomed Central}

(c) 2013 Colley et al.; licensee BioMed Central Ltd. This is an Open Access article distributed under the terms of the Creative Commons Attribution License (http://creativecommons.org/licenses/by/2.0), which permits unrestricted use, distribution, and reproduction in any medium, provided the original work is properly cited. 
(aged 1-4 years) participate in physical activity of any intensity (i.e., light, moderate or vigorous) for at least 3 hours a day [8,9]. The Canadian guidelines also recommend progression toward at least 60 minutes of energetic play (i.e., MVPA) by 5 years of age to align with the guidelines for children ages 5 to 17 years which recommend 60 minutes of MVPA per day [9]. Compliance with the recommendation of at least 180 min of physical activity at any intensity also varies considerably between countries, ranging from $5 \%$ in a sample of children from Melbourne, Australia [1] to $73 \%$ in a sample of children from Hamilton, Canada [10].

The American Academy of Pediatrics (AAP) recommends no more than 2 hours per day of television time for children aged 2 years and older [11] and the Australian Government's Department of Health and Ageing stipulates no more than one hour of screen-based entertainment per day for 3 to 5 year old children [8]. In a sample of 3 to 5 year old children from Melbourne, Australia, 22\% met the Australian recommendation $(<1 \mathrm{hr} / \mathrm{d})$ and $59 \%$ met the AAP recommendation $(<2 \mathrm{hr} / \mathrm{d})$ [1]. New Canadian sedentary behavior guidelines were released in 2012 [12]. Key aspects of the Canadian sedentary behavior guidelines are that i) children under age 2 do not engage in screen time, a recommendation consistent with the American Association of Pediatrics [11], and ii) screen time be limited to less than $1 \mathrm{~h}$ per day in 3 to 4 year old children [12], and less than 2 $\mathrm{h}$ per day in 5 year old children [13]. Data from a sample of children from Kingston, Canada indicated that less than half $(46 \%)$ of children aged 2-4 years met the Canadian screen time recommendation of $<1 \mathrm{hr} / \mathrm{d}$ [14]. It is presently unknown whether this finding is representative of children in this age group across Canada.

The measurement of physical activity and sedentary behavior in children during the early years is needed not only to estimate the proportion of the population meeting recommendations pertaining to physical activity and sedentary behavior guidelines, but to establish the relationships between these movement constructs with health outcomes, and to enable researchers to evaluate the effectiveness of interventions. Physical activity and sedentary behavior in young children can be measured using indirect (e.g., parent-report, direct observation) and direct (e.g., pedometers and accelerometers) methods. Accelerometers provide objective information on the frequency, intensity and duration of movement. Parentreported information provides important contextual information on the specific behaviors young children are engaging in while being active or sedentary [15].

It is presently unknown what proportion of a nationally representative sample of Canadian children aged 3 to 5 years is meeting these new physical activity and sedentary behavior guidelines. The $2^{\text {nd }}$ cycle of the Canadian Health Measures Survey (CHMS) collected accelerometry and parent-reported data on physical activity and sedentary behavior on a sample of children aged 3-5 years. The purpose of this paper is to report, for the first time ever on a nationally-representative sample, the physical activity and sedentary behaviors of Canadian children aged 3-5 years.

\section{Methods}

The CHMS collected data from a nationally representative sample of the population aged 3 to 79 years living in private households at the time of the survey [16]. Residents of Indian Reserves, institutions and certain remote regions, and full-time members of the Canadian Armed Forces were excluded. Approximately $96 \%$ of Canadians were represented. The survey involved an interview in the respondent's home and a visit to a mobile examination center for a series of physical measurements. Data were collected at 18 sites across Canada from August 2009 to November 2011. Ethics approval to conduct the CHMS was obtained from Health Canada's Research Ethics Board [17]. For younger children, a parent or legal guardian provided written consent and written assent was also obtained from the child. Participation was voluntary; respondents could opt out of any part of the survey at any time.

Upon completion of the mobile examination center visit, ambulatory respondents were asked to wear an Actical accelerometer (Phillips - Respironics, Oregon, USA) over their right hip on an elasticized belt during their waking hours for 7 consecutive days. The Actical (dimensions: $2.8 \times 2.7 \times 1.0$ centimetres; weight: 17 grams) measures and records time-stamped acceleration in all directions, providing an indication of movement intensity, duration and frequency. The digitized values are summed over a user-specified interval of 60 -sec, resulting in a count value per minute $(\mathrm{cpm})$. Accelerometer signals are also recorded as steps per minute. The Actical has been validated to measure physical activity and sedentary behavior in preschool aged children [18,19].

The monitors were initialized to start collecting data at midnight following the mobile examination center appointment. Respondents were blind to all data while they wore the device. The monitors were returned to Statistics Canada in a prepaid envelope, where the data were downloaded and the monitor was checked to determine if it was still within the manufacturer's calibration specifications [20]. Standard data reduction procedures were followed that are consistent with cycle 1 of the CHMS [20,21]. A valid day for this age group was defined as 5 or more hours of monitor wear time [22] and respondents with 4 or more valid days were retained for analyses [20,21,23]. Wear time was determined by subtracting non-wear time from 24 hours. Non-wear time was defined as at least 60 minutes of consecutive minutes of zero counts, with allowance for 1 to 2 minutes of counts between 0 and 100 [22,23]. 
For this study, time spent at various levels of movement intensity (sedentary, light, moderate, vigorous) was based on cut-points corresponding to each intensity level. The cut-point used for MVPA was 1,150 cpm [18]. A cut-point of $100 \mathrm{cpm}$ was used to delineate sedentary behavior from light physical activity [24]. Children aged 3-4 years were classified as meeting the guideline if they achieved $180 \mathrm{~min}$ of physical activity at any intensity every day (i.e., 180 minutes $\geq 100$ counts per minute) on all valid days (e.g. "daily"). To determine the probability that 5 year old children accumulated at least 60 minutes of MVPA at least 6 days a week, the analytical approach was harmonized with that used previously in 6-19 year old children in the CHMS [21]; an approach that was based on the technique used in the United States to analyze the 2003 to 2004 National Health and Nutritional Examination Survey (NHANES) accelerometry data [23]. To maximize the sample size, a Bayesian approach was used to incorporate the information from children with 4 or more valid days. An individual's probability of being active at least 6 days out of 7 days was estimated using a Beta distribution for the observed combination of active and wear days. The estimated population prevalence is the weighted average of these individual probabilities [25]. Progression towards meeting the physical activity guidelines of 60 daily minutes of MVPA on valid days in 3-4 year olds was assessed using the same Bayesian approach to examine the proportion of 3-4 year olds who accumulated 180 minutes of physical activity at any intensity where 10 , 20, 30, 45 and 60 minutes of that time was at least MVPA. Average daily step counts were calculated and the proportions of children accumulating an average of 6,000 steps per day and 6,000 steps on every valid day [10] were both assessed.

As part of the CHMS household questionnaire, parents were asked a series of questions about their child's level of physical activity and engagement in sedentary behaviors:

- Over the past 7 days, on how many days was he/she physically active for a total of at least 60 minutes per day? (none, 1 day, 2-3 days, 4 days or more)

- Over a typical or usual week, on how many days is he/ she physically active for a total of at least 60 minutes per day? (none, 1 day, 2-3 days, 4 days or more)

- About how many hours a week does he/she usually take part in physical activity (that makes him/her out of breath or warmer than usual) outside of school while participating in lessons or league or team sports? (never, <2 hrs/wk, 2-3 hrs/wk, 4-6 hrs/wk, 7+ hrs/wk)

- About how many hours a week does he/she usually take part in physical activity (that makes him/her out of breath or warmer than usual) outside of school while participating in unorganized activities, either on his/her own or with friends? (never, $<2$ hrs/wk, 2-3 hrs/wk, 4-6 hrs/wk, 7+ hrs/wk)

- On average, about how many hours a day does he/she watch TV or videos or play video games? (doesn't watch TV or videos or play video games, $<1 \mathrm{hr} / \mathrm{d}, 1-2 \mathrm{hrs} / \mathrm{d}, 3-4 \mathrm{hrs} / \mathrm{d}, 5-6 \mathrm{hrs} / \mathrm{d}, 7+\mathrm{hrs} / \mathrm{d})$

- On average, about how many hours a day does he/ she spend on a computer (working, playing games, e-mailing, chatting, surfing the internet, etc.)? (doesn't use a computer, $<1 \mathrm{hr} / \mathrm{d}, 1-2 \mathrm{hrs} / \mathrm{d}$, 3-4 hrs/d, 5-6 hrs/d, 7+ hrs/d)

Time spent watching TV, videos or playing video games and time spent on a computer was derived using the mid-points of the previous category (i.e. 0, 0.5, 1.5, $2.5,5.5$ and 7 hours for the respective categories). The amount of time was summed for the two questions to obtain screen time and children aged 3 to 4 with $\leq 1 \mathrm{~h} / \mathrm{d}$ of screen time or children aged 5 with $\leq 2 \mathrm{~h} / \mathrm{d}$ of screen time were deemed as following the screen time recommendations within the sedentary behavior guidelines. For example, if a parent reported $<1 \mathrm{hr} / \mathrm{d}$ for both the question about $\mathrm{TV} /$ videos and the question about computer time, that child was assigned the midpoint value of $0.5 \mathrm{hr} / \mathrm{d}$ for each to give a total equal to $1 \mathrm{hr} / \mathrm{d}$ of screen time, which is slightly different to $<1 \mathrm{hr} / \mathrm{d}$. This way of deriving screen time means that we assessed whether a child is accumulating $\leq 1 \mathrm{hr}$ of screen time per day rather than the actual guideline which is $<1 \mathrm{hr} / \mathrm{d}$.

The response rate for selected household was $75.9 \%$, meaning that in $75.9 \%$ of these households, a resident provided the sex and date of birth of all household members. One or two members of each responding household were chosen to participate in the CHMS; $92.6 \%$ of the parents of selected 3-5 year olds completed the household questionnaire, and $79.4 \%$ of this group participated in the mobile examination center component. Five children did not accept the activity monitor and 48 never returned the monitor. Of the children who participated in the mobile examination center component, $76.9 \%$ wore the accelerometer for at least 4 valid days. After adjusting for the sampling strategy, the final response rate for having a minimum of 4 valid days was $42.7 \%(75.9 \times 92.6 \times 79.4 \times 76.9)$. This article is based on 459 examination center respondents aged 3-5 years who provided a minimum of 4 days of valid accelerometer data.

All analyses were completed using SAS version 9.2 and were based on weighted data for respondents with at least 4 valid days of data. To account for survey design effects of the CHMS, standard errors, coefficients of variation, and 95\% confidence intervals were estimated using the bootstrap technique [26-28]. 


\section{Results}

Characteristics of the 459 children included in the analysis are in Table 1 . The average age of the sample was 4 years and the sex split was almost equal (50.5\% were boys). The majority $(83 \%)$ of the sample was considered healthy weight according to the International Obesity Task Force classification cut-offs [29].

\section{Meeting the physical activity guidelines based on accelerometer data}

Eighty-four percent of 3 and 4 year olds met the current physical activity guideline, defined as being active at any intensity for at least 180 minutes every day (Table 2). Ninety-eight percent were active on all valid days except one. Progression towards accumulating 60 minutes of daily MVPA as part of the 180 minutes of total physical activity (3-4 year olds) is presented in Figure 1. More than half of 3 and 4 year olds accumulated at least 20 minutes of MVPA within their 180 minutes per day of total physical activity while $11 \%$ accumulated at least 60 minutes of MVPA within their 180 minutes of total physical activity (Figure 1). Fourteen percent of 5 year olds accumulated at least 60 minutes of MVPA on at least 6 days per week (the operational definition of meeting the guideline of 60 minutes of MVPA every day).

\section{Meeting the screen time recommendation within the sedentary behavior guidelines}

Eighteen percent of children aged 3 and 4 years met the screen time recommendation within the sedentary behavior guidelines, which states that children of this age should accumulate less than 1 hour per day of screen time [12] (Table 2). Eighty-one percent of 5 year-old children met the screen time recommendations, which states that children of this age should accumulate less than 2 hours per day of

Table 1 Selected characteristics of weighted sample, by sex, household population aged 3-5 years, Canada, August 2009 to November 2011

\begin{tabular}{lcccccc}
\hline Characteristics & All & \multicolumn{2}{c}{ Boys } & \multicolumn{2}{c}{ Girls } \\
& Estimate & S.E. & Estimate & S.E. & Estimate & S.E. \\
\hline $\begin{array}{l}\text { Total sample } \\
\text { (number) }\end{array}$ & 459 & & 232 & & 227 & \\
Age (years) & 4.0 & 0.04 & 4.0 & 0.09 & 4.0 & 0.07 \\
Height (cm) & 106.4 & 0.43 & 107.0 & 0.64 & 105.7 & 0.91 \\
Weight (kg) & 18.6 & 0.19 & 19.0 & 0.33 & 18.1 & 0.39 \\
BMl (kg/m ${ }^{2}$ ) & 16.3 & 0.10 & 16.5 & 0.14 & 16.0 & 0.14 \\
BMl category & & & & & & \\
$\quad$ Healthy weight(\%) & 83.0 & 2.8 & 84.7 & 3.3 & 81.3 & 3.9 \\
$\quad$ Overweight/obese(\%) & $16.4^{\mathrm{E}}$ & 2.9 & $14.3^{\mathrm{E}}$ & 3.4 & $18.7^{\mathrm{E}}$ & 3.9 \\
\hline
\end{tabular}

E Interpret with caution.

International Obesity Task Force thresholds used to define Overweight/Obese.
Table 2 Adherence to physical activity and sedentary behaviour guidelines, household population aged 3 to 5 years, Canada, August 2009 to November 2011

\begin{tabular}{|c|c|c|c|c|}
\hline \multirow[b]{2}{*}{ Age } & \multirow[b]{2}{*}{ Target } & \multirow[b]{2}{*}{$\%$} & \multicolumn{2}{|c|}{$95 \% \mathrm{Cl}$} \\
\hline & & & From & To \\
\hline \multicolumn{5}{|c|}{ Physical activity } \\
\hline \multirow{3}{*}{3 to 4 years } & $\begin{array}{l}180 \text { minutes of total physical activity, } \\
\text { all valid days }\end{array}$ & 83.8 & 77.7 & 90.0 \\
\hline & $\geq 6,000$ steps per day (average) & 91.8 & 86.1 & 97.5 \\
\hline & $\geq 6,000$ steps per day (all valid days) & 44.7 & 33.7 & 55.6 \\
\hline \multirow{3}{*}{5 years } & $\begin{array}{l}\text { At least } 60 \text { minutes of MVPA on } \\
\text { at least } 6 \text { days }\end{array}$ & 13.7 & 9.4 & 18.0 \\
\hline & $\geq 6,000$ steps per day (average) & 87.1 & 76.7 & 97.4 \\
\hline & $\geq 6,000$ steps per day (all valid days) & 44.8 & 32.2 & 57.5 \\
\hline \multicolumn{5}{|l|}{$\begin{array}{l}\text { Sedentary } \\
\text { behaviour }\end{array}$} \\
\hline 3 to 4 years & $\begin{array}{l}\leq 1 \mathrm{hr} \text { of parent-reported average } \\
\text { daily screen time }\end{array}$ & 17.9 & 11.9 & 23.8 \\
\hline 5 years & $\begin{array}{l}\leq 2 \mathrm{hr} \text { of parent-reported average } \\
\text { daily screen time }\end{array}$ & 80.7 & 71.2 & 90.2 \\
\hline \multicolumn{5}{|c|}{ Both guidelines } \\
\hline 3 to 4 years & $\begin{array}{l}\geq 180 \text { minutes of total physical } \\
\text { activity and } \leq 1 \mathrm{hr} / \mathrm{d} \text { screen time }\end{array}$ & 15.3 & 10.3 & 20.4 \\
\hline 5 years & $\begin{array}{l}\geq 60 \text { minutes of MVPA and } \leq 2 \\
\mathrm{hr} / \mathrm{d} \text { screen time }\end{array}$ & 5.3 & 2.2 & 8.3 \\
\hline
\end{tabular}

screen time (Table 2). Fifteen percent of 3-4 year olds and $5 \%$ of 5 year olds met both the physical activity and the sedentary behavior guidelines.

\section{Average daily physical activity and sedentary behavior based on accelerometer data}

On average, 3 and 4 year-old children accumulated 352 daily minutes of total physical activity and spent $50 \%$ $\left(\sim 5.8 \mathrm{hrs} \cdot \mathrm{d}^{-1}\right)$ of their waking time per day engaged in sedentary behavior, $41 \%\left(\sim 4.8 \mathrm{hrs} \cdot \mathrm{d}^{-1}\right)$ engaged in light intensity physical activity and 9\% $\left(\sim 66 \mathrm{~min} \cdot \mathrm{d}^{-1}\right)$ of their day engaged in MVPA (Table 3). On average, 5 year old children accumulated 343 daily minutes of total physical activity and spent $53 \%\left(\sim 6.4 \mathrm{hrs} \cdot \mathrm{d}^{-1}\right)$ of their waking time per day engaged in sedentary behavior, 38\% $\left(\sim 4.6 \mathrm{hrs} \cdot \mathrm{d}^{-1}\right)$ engaged in light intensity physical activity and 9\% $\left(\sim 68 \mathrm{~min} \cdot \mathrm{d}^{-1}\right)$ of their day engaged in MVPA (Table 3$)$. The average accelerometer wear time for all children in the sample was approximately 12 hours per day.

\section{Daily step counts}

Children aged 3 and 4 years accumulated an average of 9,764 step counts per day while 5 year old children accumulated an average of 10,202 step counts per day (Table 3). The proportion of children meeting the 6,000 steps per day target is presented in Table 2 . 


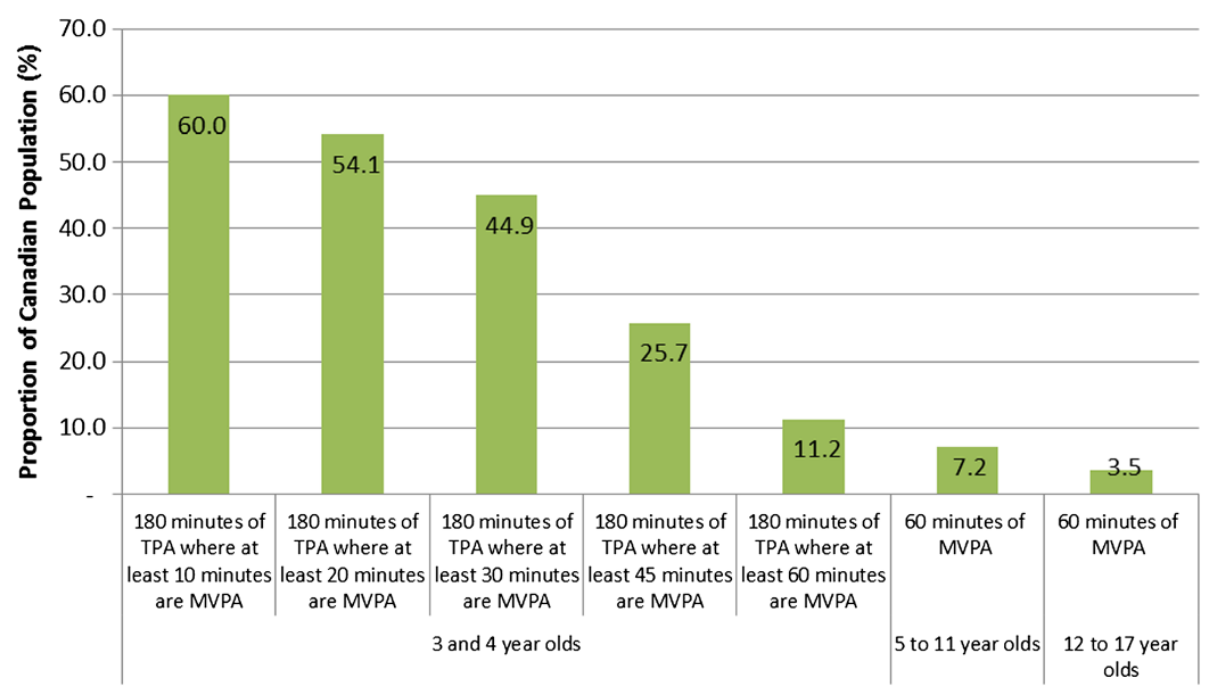

Figure 1 Compliance with moderate-to-vigorous physical activity targets, household population aged 3-17 years, Canada, August 2009 to November 2011. Note: The bars representing the 5-11 and 12-17 age ranges are included to provide context for the data presented on 3-4 year olds in this figure. The source of the data is the same for the entire age range: Cycle 2 (2009-2011) of the Canadian Health Measures Survey, Statistics Canada.

\section{Parent-reported physical activity and sedentary behavior}

Parents reported that their 3 and 4 year old children are physically active for at least 60 minutes per day on an average of 5 days a week. Parents of 3 and 4 year old children reported more unorganized compared to organized physical activity $\left(5.3 \mathrm{vs}\right.$. $\left.0.6 \mathrm{hrs} \cdot \mathrm{wk}^{-1}\right)$. The average weekly time 3 and 4 year olds spent in front of screens was $2.2 \mathrm{hrs} \cdot \mathrm{wk}^{-1}\left(1.9 \mathrm{hrs} \cdot \mathrm{wk}^{-1}\right.$ watching $\mathrm{TV} /$ video and $0.3 \mathrm{hrs} \cdot \mathrm{wk}^{-1}$ on computer). Parents reported that their 5 year old children were physically active for at least 60 minutes per day on an average of 5 days per week and engaged in more organized activity compared to younger children (1.0 vs. $\left.0.6 \mathrm{hr} \cdot \mathrm{wk}^{-1}\right)$ and similar levels of unorganized activity (5.2 vs. $\left.5.3 \mathrm{hr} \cdot \mathrm{wk}^{-1}\right)$. The average weekly time 5 year olds spent in front of screens was $1.9 \mathrm{hr} \cdot \mathrm{wk}^{-1}\left(1.4 \mathrm{hrs} \cdot \mathrm{wk}^{-1}\right.$ watching $\mathrm{TV} /$ video and $0.5 \mathrm{hrs} \cdot \mathrm{wk}^{-1}$ on computer).

\section{Discussion}

The majority of Canadian children aged 3-4 years are meeting the current physical activity guideline of at least 180 minutes of physical activity at any intensity every day [9]. This proportion is much higher when compared to older children in Canada, for whom the guideline focuses on MVPA and not total physical activity. According to the CHMS, $14 \%$ of 5 year olds met the physical activity guideline of 60 daily minutes of MVPA [30] while $7 \%$ of 5 to 11 year-olds and 3.5\% of 12 to 17 year-olds met this same guideline [31]. Eighteen percent of $3-4$ year olds and $81 \%$ of 5 year olds met the screen time recommendation within the current sedentary behavior guidelines, which recommend less than 1 hour a day of screen time in 2-4 year olds [12] and no more than 2 hours a day of screen time from age 5 to 17 [13]. Only $15 \%$ of $3-4$ year olds

Table 3 Average daily minutes of activity at various levels of intensity and average daily step counts, by age and weight status, household population aged 3 to 5 years, Canada, August 2009 to November 2011

\begin{tabular}{|c|c|c|c|c|c|c|c|c|c|c|c|c|c|c|c|c|c|c|c|c|}
\hline \multirow[b]{3}{*}{$3-4$ years } & \multicolumn{4}{|c|}{ Sedentary time } & \multicolumn{4}{|c|}{ Light physical activity } & \multicolumn{4}{|c|}{ MVPA } & \multicolumn{4}{|c|}{ Total physical activity } & \multicolumn{4}{|c|}{ Step counts } \\
\hline & \multirow{2}{*}{$\begin{array}{c}\min / \mathbf{d} \\
348\end{array}$} & \multirow{2}{*}{$\begin{array}{c}\text { S.E. } \\
7\end{array}$} & \multicolumn{2}{|c|}{$95 \% \mathrm{Cl}$} & \multirow{2}{*}{$\frac{\min / \mathbf{d}}{285}$} & \multirow{2}{*}{$\begin{array}{c}\text { S.E. } \\
5\end{array}$} & \multicolumn{2}{|c|}{$95 \% \mathrm{Cl}$} & \multirow{2}{*}{$\frac{\min / \mathrm{d}}{66}$} & \multirow{2}{*}{$\begin{array}{c}\text { S.E. } \\
3\end{array}$} & \multicolumn{2}{|c|}{$95 \% \mathrm{Cl}$} & \multirow{2}{*}{$\frac{\mathrm{min} / \mathrm{d}}{352}$} & \multirow{2}{*}{$\begin{array}{c}\text { S.E. } \\
6\end{array}$} & \multicolumn{2}{|c|}{$95 \% \mathrm{Cl}$} & \multirow{2}{*}{$\begin{array}{c}\text { steps/d } \\
9764\end{array}$} & \multirow{2}{*}{$\begin{array}{l}\text { S.E. } \\
348\end{array}$} & \multicolumn{2}{|c|}{$95 \% \mathrm{Cl}$} \\
\hline & & & 332 & 365 & & & 275 & 296 & & & 61 & 72 & & & 340 & 364 & & & 9012 & 1051 \\
\hline & $381^{*}$ & 9 & 361 & 400 & 275 & 6 & 261 & 289 & 68 & 3 & 62 & 74 & 343 & 8 & 325 & 361 & 10202 & 578 & 8954 & 114 \\
\hline & & 7 & 342 & 375 & & 4 & 273 & 290 & 68 & 2 & 62 & 73 & 349 & 5 & 337 & 361 & & 337 & 9214 & 106 \\
\hline Jverweignu/UDese & 360 & 9 & 341 & 379 & 287 & 11 & 263 & 311 & 63 & 5 & 52 & 74 & 350 & 15 & 318 & 382 & 9753 & 678 & 8290 & 112 \\
\hline
\end{tabular}

MVPA, moderate-to-vigorous physical activity.

$\mathrm{Cl}$, confidence interval.

* Significantly different to 3-4 year old children. 
and $5 \%$ of 5 year olds met both the physical activity and sedentary behavior guidelines (Table 2).

The difference in the proportion meeting the physical activity guidelines between ages $3 / 4$ years to 5 years is largely explained by the shift in volume and intensity of physical activity recommended by the different physical activity guidelines, from 180 minutes of physical activity at any intensity to 60 minutes of daily MVPA. In accelerometer data analysis, light physical activity is defined as any observations above the sedentary cut-point $(100 \mathrm{cpm})$ and therefore makes up a large proportion of the day. For example, 3 and 4 year-old children in the present analysis spent $41 \%$ (over 4 hours) of their waking hours engaged in light physical activity, and almost all children achieved the recommended 180 minutes of total physical activity every day. The physical activity guideline for children aged 0 to 4 years also states that children should progress towards accumulating 60 minutes of daily MVPA by age 5 [9]. To assess how 3 to 4 year olds were progressing towards this target, we examined the proportion that were accumulating 180 minutes of total physical activity with the added stipulation that at least $10,20,30,45$ or 60 minutes were of at least moderate intensity (Figure 1). The added 60 min MVPA requirement brought the 3 and 4 year olds to a level of meeting the guideline (11\%) that was more consistent with children aged 5-11 years (7\%). Most young children aged 3 and 4 years of age were active enough to meet the guideline; however, based on these CHMS data, the progression towards accumulating 60 minutes of daily MVPA by age 5 appears to be occurring only in a small proportion of this nationally representative sample of Canadian children.

Placing the findings of the current study in context with previous work is limited by the use of different models of accelerometers between studies, different choices of intensity cut-points, and in particular, the use of varying epoch lengths. The current study used a 60-sec epoch which is much longer than previous studies in this age group $[1,10,32,33]$. The encouraging physical activity result observed for 3 and 4 year children in the present analysis ( $84 \%$ meeting the physical activity guideline) is consistent with other data from Hamilton, Canada that reported between $73-100 \%$ of children accumulated at least 180 minutes per day of total physical activity $[10,32]$. This is in contrast to a recent study based in Melbourne, Australia that reported only $5 \%$ met the recommended minimum level of 3 hours per day of total physical activity [1]. The current study observed higher levels of total physical activity (343-352 $\mathrm{min} / \mathrm{d}$ ) compared to the two studies based in Hamilton, Ontario (252 and $220 \mathrm{~min} / \mathrm{d}$ ) [10,32] and the study based in Melbourne, Australia (127 min/d) [1]. However, in comparison to the Hamilton, Canada studies [10,30], children in the current study accumulated less MVPA (66-68 vs 75-92 min.d $\mathrm{d}^{-1}$ ). Further, Gabel and colleagues reported that $57 \%$ accumulated 60 minutes of MVPA within their 180 minutes of total physical activity [10] whereas in the present analysis, only $11 \%$ achieved the same. Hinkley and colleagues did not report daily minutes of MVPA but reported that MVPA made up a smaller proportion of waking hours compared to the current study (3.4 vs 9.5\%) [1]. The higher levels of MVPA observed in the two Hamilton, Canada studies [10,32] are consistent with a study by Vale and colleagues which observed that $93.5 \%$ and $77.6 \%$ of children accumulated $60 \mathrm{~min} \cdot \mathrm{d}^{-1}$ of MVPA on weekdays and weekends, respectively [33]. It has been suggested that longer epochs may underestimate MVPA and overestimate light intensity physical activity, especially in very young children [32,34]. The reason for this is the inability of longer epochs to capture the sporadic and intermittent nature of activity that is typical in this age group [3]. This may partially explain why the daily minutes of MVPA were lower in the current study compared to the two Hamilton, Canada studies; however, this does not explain why Hinkley and colleagues reported such low MVPA values as they also used an epoch of $15 \mathrm{sec}$. Additional differences in chosen intensity cut-points between studies may be contributing to differences in findings. Specifically, the cut-point used to delineate sedentary from light intensity physical activity in the study from Melbourne, Australia [1] was higher than other studies using the same monitor, thus leading to lower light and total physical activity. These inconsistencies in methodological design highlight the need for data harmonization to fully understand physical activity prevalence during the early years across countries.

The average daily step counts observed in the present analysis (3-4 year olds: 9,764; 5 year olds: 10,202 steps per day) are consistent with other step count data for this age group collected with both accelerometers $(8,968$ steps per day) [10] and pedometers (9,980 steps per day) [35]. Recently, a daily step target of 6,000 was proposed for the early years to be used as a step target equating to 180 minutes of total physical activity where 60 minutes are MVPA [10]. In the present study, the majority of children accumulated a weekly average of at least 6,000 steps per day (3-4 year olds: 92\%, 5 year olds: $87 \%$ ) while fewer achieved this target on all valid days (45\%). This finding highlights the limitation of a weekly average step count value to identify children who are meeting a daily target. In the current study, $84 \%$ of 3-4 year olds met the physical activity guideline according to the accelerometer results. If only step count data had been available, we would have concluded that $45 \%$ were meeting the daily guideline. Further research is needed to examine the relationships between accelerometer- and pedometermeasured physical activity at very young ages when gait patterns are still being established.

In the present analysis, only $18 \%$ of children aged 3-4 years met the sedentary behavior guideline of less than 1 
$\mathrm{h}$ per day of screen time. Carson and colleagues reported a higher proportion $(43 \%)$ of children meeting the same sedentary behavior guideline in 2-4 year old children from the Kingston, Canada health region [14]. The questions asked of parents to derive screen time were very similar between these two studies. Participants in the Kingston, Canada study were recruited primarily from registered child care centers while the CHMS recruited from a broader population that included those registered and not registered in these types of programs. It is possible that the Kingston, Canada sample reflected children of a higher socioeconomic status and with more structured days who had fewer opportunities to accumulate screen time. Also, the CHMS reflects the entire Canadian population instead of a single health region. Other countries have assessed a similar screen time target and found results consistent with ours. For example, 22\% of 3 to 5 year old Australian children accumulated $1 \mathrm{~h}$ or less of daily screen time [1]. At present the sedentary behavior guideline do not stipulate a total daily sedentary time target (i.e., that encompasses sedentary activities beyond screen time). A lower proportion of the waking hours was spent in sedentary time in the present population of 3 to 5 year old children (50\%) when compared to older children (63\%) [31] and adults (71\%) [31] in the CHMS, indicating that this age group is the least sedentary age group in the Canadian population.

Determining the proportion of children meeting physical activity guidelines using accelerometry data is largely dependent on the accelerometer cut-points used to define different levels of intensity. The MVPA cut-point recently proposed by Adolph and colleagues [18] was used in the present analysis because it was developed for Actical accelerometer data collected in 60 -sec epochs in 3-5 year old children. Further, this cut-point $(1,150 \mathrm{cpm})$ was based on an activity energy expenditure value of 0.05 $\mathrm{kcal} \cdot \mathrm{kg}^{-1} \cdot \mathrm{min}^{-1}$ or approximately $2-3$ metabolic equivalents (METS); a demarcation point consistent with that used for the moderate cut-point $\left(\geq 0.04 \mathrm{kcal} \cdot \mathrm{kg}^{-1} \cdot \mathrm{min}^{-1} ; 1,500 \mathrm{cpm}\right)$ used in older children and youth in the CHMS $[21,36]$. The only other published Actical cut-point for this age group was designed for use with 15-sec epoch data and was based on a very different methodological approach that placed the demarcation point between light and moderate at an energy expenditure level of $20 \mathrm{ml} \cdot \mathrm{kg}^{-1} \cdot \mathrm{min}^{-1}$ or approximately 5.7 METS [19]. While the appropriateness of using METS to define energy expenditure in young children has been questioned [19,37], the large gap in MET values would have rendered the physical activity estimates from 3 to 5 year old children not comparable to older children in the CHMS. Had we used the cut-point presented by Pfeiffer and colleagues (multiplied by 4 to work with 60 -sec epoch data: $2,860 \mathrm{cpm}$ ), the physical activity estimates would have been markedly different. For example, instead of a daily average of 68 minutes in 5 year old children, we would have reported only 17 minutes of daily MVPA. Further, this would have resulted in only $0.5 \%$ of 5 year olds meeting the physical activity guideline compared to the 14\% reported herein. These examples highlight the considerable impact cut-point values can have on physical activity estimates.

The results presented here provide the first estimates of the proportion meeting the physical activity and sedentary behavior guidelines on a nationally representative sample of Canadian children aged 3-5 years. The accelerometry data provide objective estimates and the parent-reported data provide important information about screen time behaviors and the context within which physical activity is accumulated in this age group (e.g., the breakdown between organized and unorganized activity). Consistent with the accelerometer data, parents reported high levels of physical activity participation in their children. As expected, time spent in unorganized activities (i.e., unstructured free play) was higher than organized activities in the younger children. Parentreported data may be impacted by recall and social desirability bias [38] and the questions used in this survey have not undergone rigorous validation testing. Accelerometers are limited in their ability to capture some activities (e.g., swimming, cycling, load bearing, incline changes) which may lead to some underestimation of overall activity. Further, the 60 -sec epoch used for data collection in the CHMS may be an additional cause of underestimation in levels of MVPA and overestimation of light intensity physical activity [32,34]. Seasonal variation could not be assessed in this sample; however, this issue is of relevance in the Canadian context [39] and should be explored in larger data sets. An important area of future research would be to examine whether enrolment in structured childcare programs impacts upon physical activity and sedentary behavior in very young children. This could not be assessed within this study because a specific question relating to childcare arrangement was not asked as part of the household survey. Also of interest would be to examine differences in physical activity and sedentary behavior between healthy weight and overweight children. This was not possible in the present analysis because of the sample size.

The transition in guidelines between age 4 and 5 years creates two challenges: i) interpreting the transition from $84 \%$ meeting the guideline at age $3-4$ years to $14 \%$ at age 5 years, and ii) understanding the required differences in analytical approach to assess the proportion meeting the physical activity guidelines. Figure 1 helps overcome the first challenge as it illustrates the impact of the progression towards the MVPA requirement on the results: $84 \%$ meet the guideline but only $11 \%$ accumulate 60 minutes of MVPA within those 3 hours. To remain consistent 
with the age brackets of the physical activity guidelines (i.e., $0-4$ years and $5-17$ years) as well as how children aged 6 years and older have been assessed previously in the CHMS [21], we used a probability function to estimate the proportion of 5 year olds meeting the guideline. This analytical approach is different to simply looking at meeting the target on all valid days, which is how $3-4$ year olds were assessed. If we had assessed 5 year olds in this way, the data would have indicated that $7 \%$ (instead of $14 \%$ ) met the physical activity guideline. The probability function is more robust when assessing low levels of adherence [21,23] and that is why we presented the $14 \%$ value as the primary finding for 5 year olds in this analysis.

\section{Conclusions}

The majority of 3 and 4 year old children in Canada are meeting current physical activity guidelines; however, only $18 \%$ are meeting their age-specific screen time recommendation within the sedentary behavior guideline. The opposite trend was observed in 5 year old children with $14 \%$ meeting their age specific physical activity guideline and the majority $(81 \%)$ meeting their screen time recommendation within sedentary behavior guideline. Overall, very few Canadian children are meeting both guidelines. Promoting physical activity while reducing sedentary behavior is important at all stages of life. The findings of the present study indicate that there remains significant room for improvement in these behaviors among young Canadian children.

\section{Competing interests}

The authors declare that they have no competing interest.

\section{Authors' contributions}

RCC conceived the idea for the manuscript, completed background analyses to inform the analysis plan, led the research team and drafted the manuscript. DG oversaw the project and completed all data reduction and statistical analysis procedures. IJ and VC provided expert analytical advice relating to accelerometry and epidemiology and provided considerable insight into the interpretation of the results. KBA, BWT and MST were involved in the analytical planning and provided critical insight during the drafting and review of the manuscript. All authors were involved in the planning of the manuscript, including conception and analytical plan. All authors have reviewed the manuscript and approved the final submitted version.

\section{Acknowledgements}

The authors acknowledge the Canadian Health Measures Survey Team within the Health Statistics Division at Statistics Canada. The authors also acknowledge John C Spence from the University of Alberta for his contribution to this work.

\section{Author details}

${ }^{1}$ Health Analysis Division, Statistics Canada, Ottawa, Canada. ${ }^{2}$ Healthy Active Living and Obesity Research Group, Children's Hospital of Eastern Ontario Research Institute, Ottawa, Canada. ${ }^{3}$ Faculty of Physical Education and Recreation, University of Alberta, Edmonton, Canada. ${ }^{4}$ School of Kinesiology and Health Studies, Queen's University, Kingston, Canada. ${ }^{5}$ Child Health \& Exercise Medicine Program, McMaster University, Hamilton, Canada.

Received: 27 February 2013 Accepted: 1 May 2013

Published: 4 May 2013

\section{References}

1. Hinkley T, Salmon J, Okely AD, Crawford D, Hesketh K: Preschoolers' physical activity, screen time, and compliance with recommendations. Med Sci Sports Exerc. doi:10.1249/MSS.0b013e318233763b. Epud ahead of print.

2. Oliver M, Schofield GM, Kolt GS: Physical activity in preschoolers Understanding measurement and prevalence issues. Sports Med 2007, 37:1045-1070

3. Tucker $P$ : The physical activity levels of preschool-aged children: $A$ systematic review. Early Childhood Res Q 2008, 23:547-558.

4. Timmons BW, Leblanc AG, Carson V, Connor Gorber S, Dillman C, Janssen I, et al: Systematic review of physical activity and health in the early years (aged 0-4 years). Appl Physiol Nutr Metab 2012, 37:773-792.

5. Leblanc AG, Spence JC, Carson V, Connor Gorber S, Dillman C, Janssen I, et al: Systematic review of sedentary behavior and health indicators in the early years (aged 0-4 years). Appl Physiol Nutr Metab 2012, 37:753-772.

6. American Alliance for Health PE, Recreation and Dance (AAHPERD): NASPE releases first ever physical activity guidelines for infants and toddlers. Illinois J Health Pe Rec Dance 2002, 50:31-32.

7. Hinkley T, Crawford D, Salmon J, Okely AD, Hesketh K: Preschool children and physical activity: A review of correlates. Am J Prev Med 2008, 34:435-441.

8. Department of Health and Ageing (DoHA): Get Up and Grow: Healthy Eating and Physical Activity for Early Childhood. 2009. Available from: http://www. health.gov.au/internet/main/publishing.nsf/Content/npra-0-5yrs-qanda.

9. Tremblay MS, Leblanc A, Carson V, Choquette L, Connor Gorber S, Dillman $C$, et al: Canadian physical activity guidelines for the early years (aged 0-4 years). Appl Physiol Nutr Metab 2012, 37:345-369.

10. Gabel L, Proudfoot NA, Obeid J, MacDonald MJ, Bray SR, Cairney J, et al: Step count targets corresponding to new physical activity guidelines for the early years. Med Sci Sports Exerc 2012. doi:10.1249/ MSS.0b013e318271765a.

11. American Academy of Pediatrics Committee on Public Education: Children, adolescents, and television. Pediatrics 2001, 107(2):423-426.

12. Tremblay MS, Leblanc A, Carson V, Choquette L, Connor Gorber S, Dillman $C$, et al: Canadian sedentary behavior guidelines for the early years (aged 0-4 years). Appl Physiol Nutr Metab 2012, 37:370-391.

13. Tremblay MS, Leblanc AG, Janssen I, Kho ME, Hicks A, Murumets $K$, et al: Canadian sedentary behavior guidelines for children and youth. Appl Physiol Nutr Metab 2011, 36:59-64. 65-71.

14. Carson V, Tremblay M, Spence JC, Timmons B, Janssen I: The Canadian sedentary behavior guidelines for the early years (zero to four years of age) and screen time among children from Kingston, Ontario. Pediatrics Child Health 2013, 18:25-28.

15. Colley RC, Wong SL, Garriguet D, Janssen I, Connor Gorber S, Tremblay MS: Physical activity, sedentary behavior and sleep in Canadian children: a comparison between parent-report and accelerometry measures and their relative association with health outcomes. Health Rep 2012, 23:1-9.

16. Tremblay MS, Wolfson M, Connor Gorber S: Canadian health measures survey: background, rationale and overview. Health Rep 2007, 18(Suppl):7-20.

17. Day B, Langlois R, Tremblay MS, Knoppers BM: Canadian health measures survey: ethical, legal and social issues. Health Rep 2007, 18(Suppl):37-52.

18. Adolph AL, Puyau MR, Vohra FA, Nicklas TA, Zakeri IF, Butte NF: Validation of uniaxial and triaxial accelerometers for the assessment of physical activity in preschool children. J Phys Act Health 2012, 9:944-953.

19. Pfeiffer KA, Mclver KL, Dowda M, Almeida MJCA, Pate RR: Validation and calibration of the Actical accelerometer in preschool children. Med Sci Sports Exerc 2006, 38:152-157.

20. Colley RC, Gorber SC, Tremblay MS: Quality control and data reduction procedures for accelerometry-derived measures of physical activity. Health Rep 2010, 21:63-69.

21. Colley RC, Garriguet D, Janssen I, Craig CL, Clarke J, Tremblay MS: Physical activity of Canadian children and youth: Accelerometer results from the 2007 to 2009 Canadian Health Measures Survey. Health Rep 2011, 22:15-23.

22. Pfeiffer KA, Dowda M, Mclver KL, Pate RR: Factors related to objectively measured physical activity in preschool children. Pediatr Exerc Sci 2009 21:196-208.

23. Troiano R, Berrigan D, Dodd K, Masse L, Tilert T, McDowell M: Physical activity in the United States measured by accelerometer. Med Sci Sports Exerc 2008, 40:181-188.

24. Wong SL, Colley RC, Connor Gorber S, Tremblay MS: Actical accelerometer sedentary activity threshold for adults. J Phys Act Health 2011, 8:587-591. 
25. National Cancer Institute, U.S. National Institutes of Health: SAS Programs for Analyzing NHANES 2003-2004 Accelerometer Data. Available at: http:// riskfactor.cancer.gov/tools/nhanes_pam.

26. Rao JNK, Wu CFJ, Yue K: Some recent work on resampling methods for complex surveys. Sun Methodology (Statistics Canada, Catalogue 12-001) 1992, 18:209-217.

27. Rust KF, Rao JNK: Variance estimation for complex surveys using replication techniques. Stat Methods Med Res 1996, 5:281-310.

28. Statistics Canada: Canadian Health Measures Survey (CHMS) Data User Guide: Cycle 2, 2012. Available at: http://www23.statcan.gc.ca/imdb-bmdi/pub/ document/5071_D2_T1_V2-eng.htm.

29. Cole TJ, Bellizzi MC, Flegal KM, Dietz WH: Establishing a standard definition for children overweight and obesity worldwide: international survey. BMJ 2000, 320:1240.

30. Tremblay MS, Warburton DE, Janssen I, Paterson DH, Latimer AE, Rhodes RE: New Canadian physical activity guidelines. Appl Physiol Nutr Metab 2011, 36:36-46.

31. Statistics Canada: Canadian Health Measures Survey (CHMS) Custom Data Tabulation. Ottawa, Canada; 2013.

32. Obeid J, Nguyen T, Gabel L, Timmons BW: Physical activity in Ontario preschoolers: prevalence and measurement issues. Appl Physiol Nutr Metab 2011, 36:291-297.

33. Vale S, Silva P, Santos R, Soares-Miranda L, Mota J: Compliance with physical activity guidelines in preschool children. J Sports Sci 2010, 28:603-608.

34. Vale S, Santos R, Soares-Miranda L, Silva P, Mota J: Preschool children physical activity measurement : importance of epoch length choice. Pediatr Exerc Sci 2009, 21:413-420.

35. Cardon G, De Bourdeaudhuii I: Comparison of pedometer and accelerometer measures of physical activity in preschool children. Pediatr Exerc Sci 2007, 19:205-214.

36. Puyau MR, Adolph AL, Vohra FL, Zakeri I, Butte NF: Prediction of activity energy expenditure using accelerometers in children. Med Sci Sports Exerc 2006, 36:1625-1631.

37. Goran MI: Measurement issues related to studies of childhood obesity: assessment of body composition, body fat distribution, physical activity, and food intake. Pediatrics 1998, 101:505-518.

38. Adamo KB, Prince SA, Tricco AC, Connor Gorber S, Tremblay MS: A comparison of indirect and direct measures for assessing physical activity in the pediatric population: A systematic review. Int J Ped Obes 2009, 4:2-27.

39. Carson V, Spence JC, Cutumisu N, Boule N, Edwards J: Seasonal variation in physical activity among preschool children in a northern Canadian city. Res Q Exerc Sport 2010, 81:392-399.

doi:10.1186/1479-5868-10-54

Cite this article as: Colley et al:: Physical activity and sedentary behavior during the early years in Canada: a cross-sectional study. International Journal of Behavioral Nutrition and Physical Activity 2013 10:54.

\section{Submit your next manuscript to BioMed Central and take full advantage of:}

- Convenient online submission

- Thorough peer review

- No space constraints or color figure charges

- Immediate publication on acceptance

- Inclusion in PubMed, CAS, Scopus and Google Scholar

- Research which is freely available for redistribution 